Annals of International Medical and Dental Research

E-ISSN: 2395-2822 | P-ISSN: 2395-2814

Vol-8, Issue-2 | March-April 2022

DOI: $10.53339 /$ aimdr.2022.8.2.10

Page no- 63-69 | Section- Research Article (Dentistry)

\title{
An In Vitro Study to Assess the Root Canal Morphology of Human Primary Molars Using Computerised Tomography
}

\author{
Shalan Kaul ${ }^{*}$, Kamna Gorka², Haridarshan Singh Sidhu ${ }^{3}$
}

\begin{abstract}
${ }^{1}$ Assistant Professor, Department of Pedodontics and Preventive Dentistry, Indira Gandhi Govt Dental College \& Hospital, Jammu, India,

Email ID: drshalankaul123@gmail.com, Orcid ID: 0000-0002-4569-3475

2Medical Officer Government Health Services, J\&K, House 158-B Hari nagar old janipur Jammu, India,

Email ID: kamnagorka@gmail.com, Orcid ID: 0000-0001-7685-4051

${ }^{3}$ Assistant Professor, Department of Pedodontic and Preventive dentistry, GDC, Patiala, Sangrur Road, Opposite Rajindra hospital, Patiala, Punjab, India, Email ID: hssidhu76@gmail.com,

Orcid ID: 0000-0002-8683-895X
\end{abstract}

*Corresponding author

Received: 09 November 2021

Revised:19 December 2021

Accepted: 01 January 2022

Published: ?

\begin{abstract}
Background: A virtuous consideration of root canal morphology is required. Complications all through and after endodontic therapy are frequently caused by variances in the anatomy of root canals in primary teeth. The goal of present study was to determine the number and shape of root canals in primary incisors and molars, as well as the pertinency of cone beam computerised tomography $(\mathrm{CBCT})$ in doing so.Material \& Methods:On a total of 60 primary molars and incisors with complete root length, CBCT was used to assess the number of roots, number of canals, width of root canal at cementoenamel junction and middle-third, length and angulations of roots. The information was statistically analysed. Results:The CBCT revealed that 13 percent of mandibular incisors had bifurcation of the root canal in the middle third, while $20 \%$ of mandibular molars had two canals in the distal root. The distobuccal root canal diameter of maxillary molars and the mesiolingual canal diameter of mandibular molars were determined to be the smallest.Conclusions:Cone beam computed tomography (CBCT) is a comparatively new and effective technology that can be used in conjunction with conventional radiography to examine variations in root canal morphology in primary teeth.
\end{abstract}

Keywords:-Pedodontics, Preventive Dentistry Cone beam computerized tomography, CBCT, primary teeth, root canal morphology.

\section{INTRODUCTION}

Radiography, methy salicylate clearance, direct observation under microscope, threedimensional (3D) reconstruction, and macroscopic sections are all used to study root canal anatomy.[1,2] In human teeth, direct examination with a microscope, macroscopic sections, filling of canals with inert material and subsequent decalcification, filling of canals, and clearing have all been done to learn more about root canal anatomy.[3,4] All of mentioned approaches, however, had significant drawbacks because the majority of the link between the exterior structure and the pulp was lost during sample processing. As a result of these flaws, 3D approaches have been developed.[5] The introduction of (3D) imaging has given clinicians a better knowledge of tooth morphology and made interactive image modification and enhancement easier, allowing them to perceive the forte as a $3 \mathrm{D}$ volume. $\frac{[6,7]}{60}$ The use of computed tomography (CT) for imaging teeth has aided breakthroughs in the field of radiology. Cone beam computerised tomography $(\mathrm{CBCT})$, the most recent technique 
Annals of International Medical and Dental Research

E-ISSN: 2395-2822 | P-ISSN: 2395-2814

Vol-8, Issue-2 | March-April 2022

DOI: $10.53339 /$ aimdr.2022.8.2.10

Page no- 63-69 | Section- Research Article (Dentistry)

established in dentistry ever since 1991 for imaging hard tissues of the maxillofacial region, has been rapidly expanding. There are various advantages to CBCT. $[8,9,10]$ First and foremost, CBCT is an office-based imaging technique that can be completed whenever needed; second, CBCT attains volumetric data in a single rotation with a short scan time; third, CBCT yields high-quality images with higher spatial resolution than multi-slice CT; and, finally, CBCT stances fewer risks to patients due to the lower radiation dose vital. In the realm of endodontics, the efficacy and significance of CBCT to the practise of endodontics is being documented with collective incidence. ${ }^{[11]}$ As a result, the purpose of this study was to determine the number and morphology of root canals in primary incisors and molars, as well as the pertinence of CBCT in determining root canal morphology in primary incisors and molars. [12]

\section{MATERIAL AND METHODS}

The study was conducted by Department of Pedodontics \& Preventive Dentistry, Indira Gandhi Govt Dental College \& Hospital, Jammu. The study used 60 molars and incisors teeth with full root length and no indications of root fracture from the sample obtained. These samples were then separated into 2 primary groups, Group A and Group B, each of which was further subdivided.

\section{Group A: Primary incisors - 30}

- Subgroup A 1 - 15 maxillary incisors

- Subgroup A 2 - 15 mandibular incisors

\section{Group B: Primary molars - 30}

- Subgroup B 1 - 15 maxillary molars
- Subgroup B 2 - 15 mandibular molars.

The teeth were washed in flowing water after being cleansed with soap. If calculus was present on the root surface, it was removed with hand scalers and preserved in individual glass containers containing a $10 \%$ formalin solution. After defining the various properties of the tooth, such as buccal, lingual, mesial, and distal, the teeth were mounted in a straight line on modelling wax to retain uniformity in the samples. The mounted teeth were then scanned with a CBCT scanner and ported to the vision preview screen for $2 \mathrm{D}$ and $3 \mathrm{D}$ reconstruction pictures in three planes, namely sagittal, axial, and coronal, using i-CAT Imaging Sciences International, Hatfield, Pennsylvania, USA, Hatfield software. Once the sample data was acquired or data for a sample was loaded the software immediately reconstructs the tooth images in sagittal, axial and coronal planes. The length and the angulation of each root were measured by taking the maximum length from the apex of the tooth to the greatest area of constriction as a cementoenamel junction (CEJ). Regardless of the varied characteristics of the canal, the diameter of each root canal was recorded at its largest diameter from the cross section of the roots.

\section{Statistical analysis}

The data collected throughout the scanning procedure was statistically analysed. For all five parameters, descriptive statistics were employed to regulate the frequency, mean, standard deviation, and range:

1. Number of roots;

2. Angulation of the roots; 
Annals of International Medical and Dental Research E-ISSN: 2395-2822 | P-ISSN: 2395-2814

Vol-8, Issue-2 | March-April 2022

DOI: 10.53339/aimdr.2022.8.2.10

Page no- 63-69 | Section- Research Article (Dentistry)

\section{Number of the root canals;}

4. Diameter of the root canals;

5. Length of the roots.

To compare the aforesaid values between subgroups A 1 and A 2, an unpaired t-test was performed, and an analysis of variance test was utilised to analyse the parameters contained by subgroups B 1 and B 2 .

\section{RESULTS}

A single canal was discovered in 87 percent of mandibular incisors, while a single canal with bifurcation in the middle-third was detected in the remaining $13 \%$ of samples. Furthermore, all mandibular molars had two canals $(100 \%)$ on the mesial root, one canal $(80 \%)$ on the distal root, and two canals on three samples of mandibular molars (20.0 percent) [Table 1] When the mean root length of incisors was compared, it was discovered that the mean root of mandibular incisors was longer than that of maxillary incisors. However, when the mean root length of molars was examined within subgroups, it was shown that the palatal root of the maxillary molar was the longest while the distobuccal root was the shortest, and that the mesial root of mandibular molars was longer than the distal root [Table 2]. When the mean angulation of root of incisors was compared to maxillary incisors, it was discovered that the angulation of root of mandibular incisors was less. The mean angulation of the mesial root was greater than that of the distal root in mandibular molars, while the difference was statistically insignificant in maxillary molars [Table 3]. The diameter of the canal was larger in maxillary incisors than in mandibular incisors, according to a comparison of mean canal diameter of incisors at CEJ. The maximum diameter in indiviual third of the root was detected in the palatal canal in maxillary molars, whereas in mandibular molars, it was seen in the distal canal [Table 4]. In comparison to mandibular incisors, the canal diameter of maxillary incisors in the middle third was larger. The palatal canal had the largest root canal diameter in maxillary molars, while the distal canal had the largest diameter in mandibular molars [Table 5].

Table 1:Number of canal in each subgroup

\begin{tabular}{|l|l|l|l|}
\hline Group & No. of canal & Frequency & Percent \\
\hline Subgroup $A_{1}$ & 1 & 15 & 100.0 \\
\hline \multirow{2}{*}{ Subgroup $A_{2}$} & 1 & 13 & 86.7 \\
\cline { 2 - 4 } & Single canal with bifurcation in middle third & 2 & 13.3 \\
\hline Subgroup $B_{1}$ & 1 & 15 & 100.0 \\
\hline Mesiobuccal & 1 & 15 & 100.0 \\
\hline Distobuccal & 1 & 15 & 100.0 \\
\hline Palatal & 2 & 15 & 100.0 \\
\hline Subgroup $B_{2}$ & 1 & 12 & 80.0 \\
\hline Mesial & 2 & 3 & 20.0 \\
\hline Distal & 2 & 3 & \\
\hline
\end{tabular}


Annals of International Medical and Dental Research E-ISSN: 2395-2822 | P-ISSN: 2395-2814

Vol-8, Issue-2 | March-April 2022

DOI: 10.53339/aimdr.2022.8.2.10

Page no- 63-69 | Section- Research Article (Dentistry)

Table 2:Length of root of each subgroup

\begin{tabular}{|c|c|c|c|c|c|c|c|}
\hline Group & Number & Minimum & Maximum & Mean & Standard deviation & t value & P value \\
\hline Subgroup $A_{1}$ & 15 & 6.40 & 9.60 & 8.14 & 0.93 & \multirow[t]{2}{*}{3.2767} & \multirow[t]{2}{*}{$0.0028 *$} \\
\hline Subgroup $A_{2}$ & 15 & 7.05 & 12.27 & 9.52 & 1.34 & & \\
\hline \multicolumn{8}{|l|}{ Subgroup $\mathrm{B}_{1}$} \\
\hline Mesiobuccal root & 15 & 6.27 & 8.90 & 7.75 & 0.77 & & \multirow[t]{3}{*}{0.347} \\
\hline Distobuccal root & 15 & 6.07 & 9.05 & 7.61 & 0.70 & & \\
\hline Palatal root & 15 & 5.68 & 9.34 & 8.03 & 0.90 & & \\
\hline \multicolumn{8}{|l|}{ Subgroup $\mathrm{B}_{2}$} \\
\hline Mesial root & 15 & 6.13 & 12.25 & 8.28 & 1.35 & & \multirow[t]{2}{*}{0.062} \\
\hline Distal root & 15 & 4.32 & 10.40 & 7.18 & 1.73 & & \\
\hline
\end{tabular}

*P value is significant at $5 \%$ level

Table 3: Angulation of root of each subgroup

\begin{tabular}{|c|c|c|c|c|c|c|c|}
\hline Group & Number & Minimum & Maximum & Mean & Standard deviation & t value & P value \\
\hline Subgroup $\mathrm{A}_{1}$ & 15 & $81.30^{\circ}$ & $99.50^{\circ}$ & $90.05^{\circ}$ & 0.93 & \multirow[t]{2}{*}{0.5767} & \multirow[t]{2}{*}{0.5688} \\
\hline Subgroup $\mathrm{A}_{2}$ & 15 & $80.90^{\circ}$ & $109.30^{\circ}$ & $91.41^{\circ}$ & 7.46 & & \\
\hline \multicolumn{8}{|l|}{ Subgroup $\mathrm{B}_{1}$} \\
\hline Mesiobuccal root & 15 & $67.00^{\circ}$ & $89.70^{\circ}$ & $81.02^{\circ}$ & 6.53 & & \multirow[t]{3}{*}{0.107} \\
\hline Distobuccal root & 15 & $67.90^{\circ}$ & $98.10^{\circ}$ & $83.80^{\circ}$ & 7.22 & & \\
\hline Palatal root & 15 & $67.90^{\circ}$ & $88.90^{\circ}$ & $78.47^{\circ}$ & 6.38 & & \\
\hline \multicolumn{8}{|l|}{ Subgroup $B_{2}$} \\
\hline Mesial & 15 & $78.8^{\circ}$ & $90.6^{\circ}$ & $84.90^{\circ}$ & 3.92 & & \multirow[t]{2}{*}{0.488} \\
\hline Distal & 15 & $81.0^{\circ}$ & $89.0^{\circ}$ & $85.71^{\circ}$ & 2.14 & & \\
\hline
\end{tabular}

${ }^{*} \mathrm{P}$ value is significant at $5 \%$ level

Table 4: Diameter of canals at CEJ in each subgroup

\begin{tabular}{|c|c|c|c|c|c|c|c|}
\hline Group & Number & Minimum & Maximum & Mean & Standard deviation & t value & P value \\
\hline Subgroup $A_{1}$ & 15 & 1.27 & 3.01 & 2.10 & 0.52 & \multirow[t]{2}{*}{4.3967} & $0.0001^{*}$ \\
\hline Subgroup $A_{2}$ & 15 & 0.90 & 1.82 & 1.44 & 0.26 & & \\
\hline \multicolumn{7}{|l|}{ Subgroup $B_{1}$} & \\
\hline Mesiobuccal & 15 & 0.90 & 1.80 & 1.18 & 0.26 & & \multirow[t]{3}{*}{$0.000^{*}$} \\
\hline Distobuccal & 15 & 0.40 & 1.45 & 1.17 & 0.25 & & \\
\hline Palatal & 15 & 1.90 & 3.20 & 2.56 & 0.37 & & \\
\hline \multicolumn{8}{|l|}{ Subgroup $\mathrm{B}_{2}$} \\
\hline Mesiobuccal & 15 & 0.71 & 1.50 & 1.15 & 0.25 & & \multirow[t]{5}{*}{$0.000^{*}$} \\
\hline Mesiolingual & 15 & 0.50 & 1.68 & 1.03 & 0.34 & & \\
\hline Distal & 12 & 1.80 & 3.82 & 2.48 & 0.65 & & \\
\hline Distobuccal & 3 & 1.01 & 2.02 & 1.43 & 0.52 & & \\
\hline Distolingual & 3 & 0.80 & 0.90 & 0.86 & 0.06 & & \\
\hline
\end{tabular}

${ }^{*} \mathrm{P}$ value is significant at $5 \%$ level, $\mathrm{CEJ}=$ Cementoenamel junction 
Annals of International Medical and Dental Research E-ISSN: 2395-2822 | P-ISSN: 2395-2814

Vol-8, Issue-2 | March-April 2022

DOI: 10.53339/aimdr.2022.8.2.10

Page no- 63-69 | Section- Research Article (Dentistry)

Table 5: Diameter of canals at middle third in each subgroup

\begin{tabular}{|c|c|c|c|c|c|c|c|}
\hline Group & Number & Minimum & Maximum & Mean & Standard deviation & t value & P value \\
\hline Subgroup $A_{1}$ & 15 & 0.90 & 2.85 & 1.69 & 0.58 & \multirow[t]{2}{*}{3.0532} & \multirow[t]{2}{*}{$0.0049 *$} \\
\hline Subgroup $A_{2}$ & 15 & 0.71 & 1.75 & 1.16 & 0.34 & & \\
\hline \multicolumn{8}{|l|}{ Subgroup $\mathrm{B}_{1}$} \\
\hline Mesiobuccal & 15 & 0.30 & 1.20 & 0.97 & 0.22 & & \multirow[t]{3}{*}{$0.002 *$} \\
\hline Distobuccal & 15 & 0.29 & 1.12 & 0.85 & 0.22 & & \\
\hline Palatal & 15 & 0.45 & 2.38 & 1.33 & 0.53 & & \\
\hline \multicolumn{8}{|l|}{ Subgroup $\mathrm{B}_{2}$} \\
\hline Mesiobuccal & 15 & 0.35 & 2.06 & 0.96 & 0.44 & & \multirow[t]{5}{*}{$0.000^{*}$} \\
\hline Mesiolingual & 15 & 0.25 & 1.12 & 0.68 & 0.24 & & \\
\hline Distal & 12 & 0.35 & 3.72 & 1.70 & 0.90 & & \\
\hline Distobuccal & 3 & 0.79 & 1.52 & 1.10 & 0.38 & & \\
\hline Distolingual & 3 & 0.56 & 0.79 & 0.69 & 0.12 & & \\
\hline
\end{tabular}

${ }^{*} \mathrm{P}$ value is significant at $5 \%$ level

\section{DISCUSSION}

The incapacity to recognise and so appropriately deal with every canal of the root canal organization is extensively acknowledged as the leading etiologic aspect of root canal treatment failure. $[10,11,12]$ The number of canals was one, but in case of mandibular incisors, single canal was seen in $87 \%$ while in the remaining $13 \%$, a single canal with bifurcation in middle-third was seen. It correlates to Type III canal configuration of permanent teeth by Vertucci,[11] but these findings are in contrast to the finding reported by Zurcher, $[13]$ which exhibited the existence of two canals in less than $10 \%$ of cases. The mesial root of primary mandibular molars had two canals in $100 \%$ of the samples, namely mesiobuccal and mesiolingual, while the distal root had two canals in $20 \%$ of the studys and one canal in the remaining $80 \%$ of the samples. Hibbard and Ireland,[14] Zoremchhingi et al.[2] and Aminabadi et al.[15] found more than one canal in $25 \%, 40 \%$, and $20 \%$ of distal roots, respectively, but only one canal in each of the mesiobuccal, distobuccal, and palatal roots in Subgroup B 1. Yang et al.[16] found in another study published in 2012 that extensive acquaintance of roots and root canal architecture is necessary to increase endodontic accomplishment in primary teeth. The mainstream of primary mandibular second molars had three to four canals, according to the author, and comparable results were obtained in the current study. Mean root length of maxillary incisors was found to be $8.14 \mathrm{~mm}$ with the maximum and minimum root length was 9.60 and $6.40 \mathrm{~mm}$, respectively, these findings are in contrast to Parab (10.00 $\mathrm{mm})$.[17] In mandibular incisors, the mean root length was $9.52 \mathrm{~mm}$, but the root length reported by Parab was less compared to the present study.17] In maxillary molars, the palatal root was found to be longest compared to mesiobuccal and distobuccal, which was in accordance with Zoremchhingi et al.[2] In this present study, there was a discrepancy between the length of mesial root of mandibular molar and the length of root given 
Annals of International Medical and Dental Research

E-ISSN: 2395-2822 | P-ISSN: 2395-2814

Vol-8, Issue-2 | March-April 2022

DOI: $10.53339 /$ aimdr.2022.8.2.10

Page no- 63-69 | Section- Research Article (Dentistry)

by Zoremchhingi et al. $(7.57 \mathrm{~mm})$ and Parab. [2,17] The difference in the fallouts of the present study and the study conducted by Parab can be attributed to the fact that in this study samples were limited to only Indian residents, [17] whereas the samples for Black study were selected from US population and the radiographs were taken to study the morphology of primary teeth. The present study ascertained that the angulation of root of mandibular incisors $\left(91.41^{\circ}\right)$ was more as compared to that of maxillary incisors $\left(90.05^{\circ}\right)$. On comparing the mean angulation of root of maxillary incisor and mandibular incisor, no significant difference was found. In maxillary molars the distobuccal root had the maximum angulation of $98.10^{\circ}$ with a mean of $83.80^{\circ}$ and minimum angulation was seen in case of mesiobuccal root of $67.00^{\circ}$ with a mean of $81.02^{\circ}$. However, these observations are a contrast to what Zoremchhingi et al.[2] reported, but in subgroup B 2 the findings are favoured by the observations reported by Zoremchhingi et al.[2] The diameter of canals was guaged at the CEJ and at the middle third. In incisors, the diameter of canals was more at the CEJ area compared with the middle-third, which depicts the tapering of the canal from CEJ to the middle-third. Comparison of mean canal diameter of maxillary incisors and mandibular incisors exhibited that the diameter of the canal was more in maxillary incisors both at CEJ and middle-third. In maxillary molars, the palatal canal exhibited the maximum diameter, which was found in accord with the studys accomplished by Zoremchhingi et al.[2] and Aminabadi et al.[15] whereas the findings of subgroup B2, showed maximum diameter of the canal at CEJ in distal root.

\section{CONCLUSIONS}

The root canals of maxillary incisors tapered more gradually than those of mandibular incisors, according to our findings. Mandibular incisor roots were discovered to have higher angulation than maxillary incisor roots. Only $13 \%$ of mandibular incisors had bifurcation of the root canal in the central portion of the tooth. The maxillary molar's distobuccal root canal was discovered to be the thinnest, while the mandibular molar's mesiolingual canal was revealed to be the thinnest. The distobuccal root of the maxillary molar was discovered to be the smallest, while the palatal root of the maxillary molar was shown to be the longest. The mesial root of mandibular molars was longer than the distal root. In $20 \%$ of people, the distal root of their mandibular molars had two canals: distobuccal and distolingual. The primary maxillary molar's distobuccal root was found to be more divergent than the other two roots, whereas the primary mandibular molar's mesial root was shown to be more divergent than the distal root. The root canal diameter, angulation, and morphology of primary teeth were studied using CBCT, which proved to be an effective and accurate diagnostic technique.

\section{REFERENCES}

1. Sandhya R, Velmurugan N, Kandaswamy D. Assessment of root canal morphology of

mandibular first premolars in the Indian population using spiral computed tomography: an in vitro study. Indian J Dent Res. 2010;21(2):169-73. doi: 10.4103/0970-9290.66626. 
Annals of International Medical and Dental Research

E-ISSN: 2395-2822 | P-ISSN: 2395-2814

Vol-8, Issue-2 | March-April 2022

DOI: 10.53339/aimdr.2022.8.2.10

Page no- 63-69 | Section- Research Article (Dentistry)

2. Zoremchhingi, Joseph T, Varma B, Mungara J. A study of root canal morphology of human primary molars using computerised tomography: an in vitro study. J Indian Soc Pedod Prev Dent. 2005;23(1):712. doi: $10.4103 / 0970-4388.16019$.

3. Nattress BR, Martin DM. Predictability of radiographic diagnosis of variations in root canal anatomy in mandibular incisor and premolar teeth. Int Endod J. 1991;24(2):58-62. doi: 10.1111/j.13652591.1991.tb00808.x.

4. Sempira HN, Hartwell GR. Frequency of second mesiobuccal canals in maxillary molars as determined by use of an operating microscope: a clinical study. J Endod. 2000;26(11):673-4. doi: 10.1097/00004770-200011000-00010.

5. Salama FS, Anderson RW, McKnight-Hanes C, Barenie JT, Myers DR. Anatomy of primary incisor and molar root canals. Pediatr Dent. 1992;14(2):1178.

6. Mohler WA. Visual reality: using computer reconstruction and animation to magnify the microscopist's perception. Mol Biol Cell. 1999;10(10):3061-3065. doi:10.1091/mbc.10.10.3061

7. Ayhan H, Alacam A, Olmez A. Apical microleakage of primary teeth root canal filling materials by clearing technique. J Clin Pediatr Dent. 1996;20:1137.

8. Gava MM. What the general practitioner should know about cone beam computed tomography technology. OHDMBSC. 2009;8:14-21.

9. Sinanoglu A, Helvacioglu-Yigit D, Mutlu I. Use of cone-beam computed tomography and threedimensional modeling for assessment of anomalous pulp canal configuration: a case report. Restor Dent Endod. 2015;40(2):161-5. doi: 10.5395/rde.2015.40.2.161.

10. Weine FS, Healey HJ, Gerstein H, Evanson L. Canal configuration in the mesiobuccal root of the maxillary first molar and its endodontic significance. Oral Surg Oral Med Oral Pathol. 1969;28(3):419-25. doi: 10.1016/0030-4220(69)902370.

11. Vertucci FJ. The endodontic significance of the mesiobuccal root of the maxillary first molar. US Navy Med. 1974;63(5):29-31.

12. Zhang R, Yang H, Yu X, Wang $\mathrm{H}, \mathrm{Hu} \mathrm{T}$, Dummer PM. Use of CBCT to identify the morphology of maxillary permanent molar teeth in a Chinese subpopulation. Int Endod J. 2011;44(2):162-9. doi: 10.1111/j.1365-2591.2010.01826.x.

13. Mohammadzadeh Akhlaghi N, Khalilak Z, Vatanpour $\mathrm{M}$, et al. Root Canal Anatomy and Morphology of Mandibular First Molars in a Selected Iranian Population: An In Vitro Study. Iran Endod J. 2017;12(1):87-91. doi:10.22037/iej.2017.18

14. Fumes AC, Sousa-Neto MD, Leoni GB, Versiani MA, da Silva LA, da Silva RA, Consolaro A. Root canal morphology of primary molars: a microcomputed tomography study. Eur Arch Paediatr Dent. 2014;15(5):317-26. doi: 10.1007/s40368-0140117-0.

15. Aminabadi NA, Farahani RM, Gajan EB. Study of root canal accessibility in human primary molars. J Oral Sci. 2008;50(1):69-74. doi: 10.2334/josnusd.50.69.

16. Yang R, Yang C, Liu Y, Hu Y, Zou J. Evaluate root and canal morphology of primary mandibular second molars in Chinese individuals by using cone-beam computed tomography. J Formos Med Assoc. 2013;112(7):390-5. doi: 10.1016/j.jfma.2012.10.008.

17. Parab S, Bhalerao S. Study designs. Int J Ayurveda Res. 2010;1(2):128-131. doi:10.4103/0974-7788.64406

Source of Support: Nil, Conflict of Interest: None declared 